2. Круглова, М.С. Совершенствование управления деятельностью волонтерских организаций на примере высших учебных заведений : дис. ... канд. экон. наук : 08.00.05 / М.С. Круглова. - Сочи, 2017. - 171 с.

3. Кульпединова, М.Е. Воспитательные возможности детских общественных объединений / М.Е. Кульпединова // Воспитание детей - инвестиции в будущее! : сб. статей Всероссийского форума (г. Владимир, 8-10 сентября 2016 г.) / отв. редактор. А.А. Сергеенко. - Москва : ИИУ МГОУ, 2016. - С. 182-188.

4. Сережникова, Р.К. Ценностно-синергетический подход к организации педагогического процесса в высшей школе / Р.К. Сапожникова // Высшее образование в России. - 2012. - № 3. - С. 77-81.

5. Сластенин, В.А. Педагогика / В.А. Сластенин, И.Ф. Исаев, Н.Н. Шиянов. - Москва : Академия, $2004 .-576$ с.

\title{
Гусева А.X. \\ О модификации методических подходов в преподавании профессиональных дисциплин лингвистам: концепция и практика
}

ФГБОУ ВО «Российский государственный гуманитарный университет»

(Россия, Москва)

doi: 10.18411/trnio-11-2021-148

\section{Аннотация}

Публикация посвящена содержательному обновлению дисциплин профессионального цикла в системе ВО. В работе представлена комбинаторная методика преподавания образовательного модуля «Технологии перевода» студентам-лингвистам, описана методическая концепция, приведены примеры из практики ведения занятий, а также проанализированы основные инструменты программных продуктов, изучаемых студентами в процессе освоения рассматриваемой дисциплины.

Ключевые слова: технологии перевода, профессиональные компетенции, методика преподавания, комбинаторная методика, программное обеспечение, цифровые инструменты, модуль системы перевода.

\section{Abstract}

The publication is devoted to the substantive renewal of the disciplines of the professional cycle in the HE system. The paper presents a combinatorial methodology for teaching the educational module «Translation Technologies» to linguistic students, describes the methodological concept, gives examples from the practice of conducting classes, and analyzes the main tools of software products studied by students in the process of mastering the discipline in question.

Keywords: translation technologies, professional competencies, teaching methods, combinatorial methods, software, digital tools, translation system module.

В связи с введением режима самоизоляции представители многих профессий были вынуждены освоить коммуникационные платформы и интернет-сервисы, позволяющие работать в режиме онлайн, проводить совещания, редактировать документы и обмениваться ими по электронной почте, чатам, коммуникационным платформам, корпоративной сети. Отметим, что профессия переводчика и ранее подразумевала удаленную работу с использованием различных цифровых инструментов, что явилось несомненным стимулом для разработчиков новых версий ПО.

На современном этапе развития специализированного программного обеспечения переводчика, а также в связи с широким распространением коммуникационных платформ, работодатели предъявляют к выпускникам вузов повышенные требования к владению информационно-коммуникационными технологиями в процессе перевода. Именно данным фактом и объясняется введение в обязательную программу обучения образовательного модуля «Технологии перевода» для студентов 5 курса Института лингвистики ФГБОУ ВО РГГУ.

Образовательный модуль «Технологии перевода» позволяет определить степень применения специализированного программного обеспечения переводчика в 
профессиональной переводческой деятельности, а также освоить определенные стратегии и технологии перевода специализированных гипертекстов и текстовых корпусов.

Профессиональные компетенции будущих переводчиков, формируемые и совершенствуемые в процессе освоения программы, являются обязательными для грамотной и эффективной профессиональной деятельности вне зависимости от области работы художественный перевод, обработка иноязычных материалов, копирайтинг на иностранном языке, редакторская деятельность, сфера СМИ, устный перевод, спецперевод (технический, финансовый, юридический, экономический и т.д.).

Для преподавания данного образовательного модуля разработана комбинаторная методика, суть которой состоит в овладении практическими навыками работы в различных системах автоматизированного перевода, освоении ПО и словарных баз данных, утилит онлайн и оффлайн, а также в обучении применяемым в практической деятельности переводческого сообщества функциональным приемам работы в информационном пространстве с использованием ИКТ, аппаратного и программного обеспечения. Достижению вышеназванных целей способствует приобретение базовых знаний о сетевых методиках индивидуальной и коллективной обработки иноязычного гипертекста специализированной тематики, обучение работе с многоязычной базой данных и создание собственного электронного глоссария, а также формирование осознания роли и места ПО при организационно-управленческой деятельности переводческих агентств.

Каково основное преимущество комбинаторной методики? С одной стороны, комбинаторика в языкознании понимается как «свойство единиц языка и соответствующих им единиц речи вступать в синтагматические отношения, то есть в отношения сочетаемости» (2, с.142). С другой, изначально являясь дисциплиной фундаментальной математики, комбинаторная методика предполагает структурирование целого и его частей с помощью различных приемов комбинирования. Автор данной статьи предлагает рассматривать комбинаторику как методику преподавания - основную дидактическую технологию проектирования образовательного модуля «Технологии перевода».

Комбинаторная методика позволяет преподавателю экспериментировать, моделировать такие вариативные образовательные модули, а также решает задачу профессионального использования иноязычных информационных посредников. Роль преподавателя состоит в организации познания, верной учебно-научной ориентации студентов, приобретении ими умения корректной ориентации в многообразной иноязычной информационной сети. Можно сказать, что проведение практических занятий в данном случае можно рассматривать как мониторинг их прогресса в переводческой деятельности, модерацию процесса коммуникации в переводческом сообществе, а также профессиональную ориентацию.

В соответствии с классификацией известного переводчика-исследователя В. $\mathrm{H}$. Шевчука, электронные системы, необходимые для освоения и профессионального использования лингвисту и переводчику, подразделяются на следующие группы: «информационные - системы, которые обеспечивают автоматический поиск лингвистической и экстралингвистической информации в Интернете, а также управление информационными потоками (энциклопедии, электронные библиотечные каталоги, банки терминов, серверы поиска и т. д.); переводческие - системы машинного перевода типа PROMT, Translation Memory, StyleWriter, Transcheck и т. д.; коммуникационные - системы, которые обеспечивают общение переводчика с заказчиком через электронную почту и с коллегами через переводческие порталы и сайты» $(5$, с.18). Перечисленные в определении модули и системы перевода изучаются в ознакомительном порядке и, в зависимости от оптимального функционала и в соответствии с тематикой и видом перевода, отбираются для работы по индивидуальным проектам. Критический анализ ресурсов позволяет студентам сформировать навыки профессионального перевода и обеспечивает экономию времени при обработке гипертекстового формата. 
Освоение профессиональных инстрментов базируется я на методе осмысленного запоминания, «преимущество которого существенно отражается на полноте, скорости, точности и прочности запоминания, а основными приемами логической обработки являются: выделение смысловых частей, составление плана и соотнесение смысловых фрагментов между собой и с ранее известным; формирование приемов смысловой, логической обработки запоминаемого материала является основным средством развития памяти и эффективности ее работы» $(1$, с.180).

Следует уточнить, что методическая концепция образовательного модуля основана на изучении и обработке материалов цифровых образовательных ресурсов, а также на анализе, комментировании, реферировании и обобщении результатов научных исследований с использованием современных отечественных и зарубежных методик и методологий. Предметная область: компаративный анализ и типологизация текстов различной тематики, обработка иноязычного гипертекста, составление корпусов текстов, работа с многоязычной базой данных, разработка интерактивного тематического глоссария, а также прикладная (переводческая, редакторская) деятельность в области языковой, профессиональной и социокультурной коммуникации. В процессе обучения переводу студенты анализируют корреляционные процессы в лингвистике, филологии, лингвокультурологии, гуманитарном знании, информатике и практике перевода на современном этапе развития ИКТ.

В соответствии с практико-ориентированной концепцией освоения программы студенты выполняют задания в последовательном либо параллельном режимах в ПО по блок-схемам, передаваемым в электронном виде, создают эссе-презентации, лексикографические базы данных, комментированные глоссарии, корпусы текстов по выбранным областям гуманитарного знания.

Безусловно, перечисленные виды переводческой деятельности в основе своей подразумевают объемную и трудоемкую работу, связанную с изучением корпусов специализированных гипертекстов и лексикографических источников, иноязычного лексикограмматического материала, а также просмотром и отбором мультимедийных материалов. В этой связи в качестве базы для выполнения интерактивных заданий предлагается список цифровых источников, который студенты должны обязательно дополнить, а также аргументировать свой выбор.

Учитывая требования работодателей и практически повсеместное использование агентствами переводов и крупными корпорациями двух последних систем перевода, автор комбинаторной методики преподавания раздела «Технологии перевода» уделяет большее внимание ПО Trados Studio Professional. Данное ПО является единой информационной средой для перевода и редактирования, управления переводческими проектами, упорядочения корпоративной терминологии и подключения сервисов машинного перевода. Bсе инструменты, необходимые для выполнения перевода, работы с терминологией и управления проектами действуют в рамках одной платформы. Среди инновационных функций, повышающих эффективность перевода, следует назвать такие, как:

1. интеллектуальная подстановка и инструменты проверки качества;

2. расширенные возможности для взаимодействия с редакторами;

3. автоматизация рутинных задач и разнообразные отчеты для эффективного управления проектами;

4. легкость изучения, простота использования и настраиваемое рабочее пространство;

5. поддержка файлов всех основных форматов (как MS Word так и специализированных форматов, например, Adobe InDesign);

6. мощные инструменты для максимального использования готовых переводов;

7. повышение удобства работы экспертов благодаря возможности редактирования переводов в среде MS Word; 
8. расширение базовых возможностей системы с помощью приложений портала SDL OpenExhcnage;

9. открытые API как возможность глубокой интеграции и настройки;

10. интеграция в программу модулей терминологического поиска и машинного перевода (3, с.17).

На первом этапе практической работы студенты разрабатывают индивидуальную систему переводов, так как указанный программный продукт позволяет создать первоначальную базу переводов на основе ранее переведенных документов. Для создания новой базы переводов необходимо загрузить исходный и соответствующий ему переведенный файл в систему, после чего программа автоматически выполнит их объединение и создаст базу переводов для будущих проектов, а технология объединения автоматически сопоставляет исходный и переведенный контент. Настройка рабочего пространства для студентов не представляет сложности, поскольку современный, интуитивно понятный интерфейс SDL Trados Studio знаком всем пользователям приложений MS Office. Рабочее пространство легко модифицируется, позволяя создать идеальную среду для перевода. Для большего удобства окно предварительного просмотра можно вынести на отдельный экран, а окно редактора переместить в верхнюю часть экрана. Инструменты, команды, справочные ресурсы логически сгруппированы, что позволяет быстро найти все необходимое. В любой момент можно вернуться к исходному расположению окон.

Механизм памяти перевода дополняет высокоскоростной перевод, в систему включено множество инновационных функций и инструментов, позволяющих ускорить перевод практически в два раза. Перечислим необходимые для обработки корпуса текстов:

1. интеллектуальный ввод на основе технологии SDL Autosuggest, увеличивающий производительность на 20\% (программа отслеживания ручного ввода, представляющая список предложенных слов или фраз в контексте и на целевом языке);

2. автоматическая подстановка форматирования или функция «Quick Place» (программное обеспечение Lotus для совместной работы в режиме реального времени между участниками из географически рассредоточенных районов);

3. инструменты контроля качества, выявляющие возможные ошибки;

4. разнообразные фильтры, позволяющие редакторам сконцентрироваться на определенной части перевода;

5. поддержка режима отображения правок в файлах MS Word, которая помогает переводчикам и редакторам беспрепятственно отслеживать все изменения в документе.

Важно упомянуть о том, что использование в преподавании практики перевода связано не только со сменой методической парадигмы, но и с техническим и технологическим оснащением процесса обучения, что отражено «в широком использовании новых лингводидактических средств - мультимедийных компьютерных программ с видеоматериалами. Преимуществами этих средств является следующее: они дают возможность придать эффект новизны традиционному аудиторному занятию, позволяют пользователю как визуально знакомиться с содержанием информации, так и оперативно получать новый информационный продукт в объеме и формате в соответствии с лингводидактической ситуацией» $(4$, с.147).

SDL Trados Studio - модульная система, и для студентов дополнительной мотивацией является возможность коллективной обработки текста или текстового корпуса. Корректно и логично структурированные модули TMS (Translation Management System) и PM (Project Management) позволяют управлять крупными многоязычными проектами. Создание проекта, включающего большое количество файлов и несколько языков перевода не составляет труда для переводчиков, использующих данный модуль. Благодаря удобной структуре подпроектов, содержащих назначенные файлы, базы переводов и терминологические базы, переводчики могут полностью сконцентрироваться на выполнении перевода. Проверка 
соответствий на уровне документа и абзацев с помощью технологии SDL Perfect Match обеспечивает особенно эффективную работу с часто обновляемыми проектами. SDL Perfect Match - форма соответствия контекста, которая сравнивает обновленные исходные файлы с соответствующим набором существующих двуязычных документов, а не с памятью переводов. Сегментные совпадения (Perfect Matches) проверяют окружающие записи, чтобы убедиться, в совпадении. Кроме того, если существующий двуязычный документ был сегментирован некорректно с текущим документом или объединил сегменты, Perfect Match может динамически объединять до трех последовательных сегментов в текущем документе, чтобы улучшить результаты соответствия.

В заключение отметим, что комбинаторная методика преподавания образовательных модулей, направленных на формирование прикладных профессиональных компетенций переводчика, обеспечивает новый, более вариативный методический подход. Предлагаемая технология обработки корпуса текстов и гипертекста является эффективным инструментом профессионального перевода, а освоение студентами SDL показывает, что активное использование ПО способствует овладению переводческими навыками и позволяет сформировать четкое представление о системах перевода, что соответствует современным требованиям работодателей.

1. Азимов Э. Г., Щукин А. Н. Новый словарь методических терминов и понятий (теория и практика обучения языкам). М.: Издательство ИКАР, 2009. 448 с.

2. Влавацкая М. В. Теоретические проблемы комбинаторной лингвистики. Лексикология. Лексикография : монография / М. В. Влавацкая. Новосибирск: НГТУ, 2011. 508 с.

3. Системы Translation Memory TRADOS, URL http://www.russiantranslators.ru/docs/TRADOS_ProductGuide.pdf/ (дата обращения - 23.10.21).

4. Терехова Е.В. Современные тенденции развития автоматизированного перевода // Научный вестник Воронеж. гос. арх.-строит. ун-та. Современные лингвистические и методико-дидакические исследования. 2006. Вып. № 5. С. 146-152.

5. Шевчук В. Н. Информационные технологии в переводе. Электронные ресурсы переводчика 2. М.: Зебра Е, 2013. $384 \mathrm{c}$.

\section{Гусева А.X.}

\section{Совершенствование организации оценивания знаний студентов в условиях адаптации ВО к системе зачетных единиц}

ФГБОУ ВО «Российский государственный гуманитарный университет»

(Россия, Москва)

doi: 10.18411/trnio-11-2021-149

\section{Аннотация}

В статье рассмотрены способы организации оценивания знаний студентов в условиях адаптации ВО к европейской системе зачетных единиц. Приведены основные положения методики оценивания и соотношение шкал оценки результатов учебной деятельности, проанализирована новая образовательная парадигма, разработанная в РГГУ в соответствии с переходом на ФГОС 3+. Описана система контроля знаний по дисциплине «Компьютерное обеспечение переводческой деятельности», разработанная в соответствии с учебным планом, определяющим виды и формы текущего и промежуточного контроля.

Ключевые слова: образовательная деятельность, оценивание знаний, шкала оценки результатов, реализация процесса обучения, аудиторная учебная работа, внеаудиторная учебная работа, текущая аттестация, промежуточная аттестация.

\section{Abstract}

The article discusses the ways of organizing the assessment of students' knowledge in the context of HE adaptation to the European credit system. The main provisions of the assessment methodology and the ratio of the scales for assessing the results of educational activities are 